\title{
Techno Girls: oficinas de programação de jogos para estudantes de escolas públicas
}

\author{
Waine Teixeira Júnior, Lohana Santos, André Manzano, Ângela Farias, Tamyres \\ Souza, Issufi Badji, Soraia Silva Prietch, Roger Resmini
}

Curso de Sistemas de Informação - Universidade Federal de Mato Grosso (UFMT) Av. dos Estudantes, 5055 - 78735-901, Rondonópolis - MT - Brasil

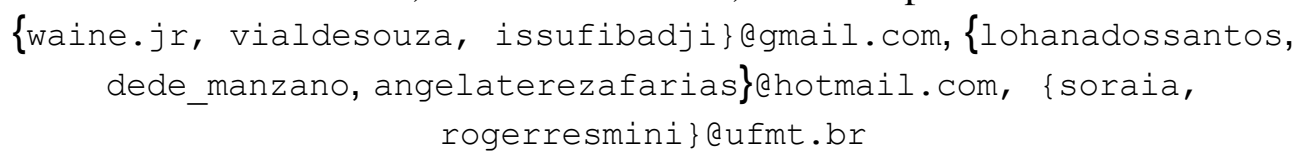

Abstract. This paper describes the experience of planning and executing workshops that integrate the following content: women in computing, hardware and software fundamentals, game programming using Python, and local job opportunities in computing. The Program offered 03 workshops, with 08 meetings of 04 hours each, for students of a state public school in the periphery of the city. The workshops were offered as a way to attract the interest of girls to the area, however, boys could also participate. The use of the Dialogic Learning approach was the differential of this Program, since its principles guided all actions and activities carried out.

Resumo. Este artigo descreve o relato de experiência do planejamento e da execução de oficinas que integram conteúdos sobre mulheres na computação, fundamentos de hardware e software, programação de jogos usando Python e o mercado de trabalho local na área de informática. O Programa ofertou 03 turmas, com 08 encontros de 04 horas cada, dessa oficina, para estudantes de uma escola pública estadual de bairro periférico da cidade. As oficinas foram oferecidas como forma de atrair o interesse de meninas para a área, no entanto, meninos também puderam participar. $O$ uso da abordagem de Aprendizagem Dialógica foi o diferencial desse Programa, uma vez que seus princípios nortearam todas as ações e atividades realizadas.

\section{Introdução}

Embora as mulheres sejam a maioria nos cursos de Ensino Superior, esse quantitativo não reflete a realidade da presença feminina nas carreiras e cursos das áreas de Computação e tecnologias [Grossi et al., 2016].

Segundo Posser e Teixeira [2016], o número de ingressantes mulheres nos cursos de graduação da área de Computação é de aproximadamente $15 \%$, enquanto em um levantamento feito em 2010, reporta que apenas $20 \%$ do universo, de cerca de 520 mil pessoas, que trabalhavam com Tecnologia da Informação no Brasil eram mulheres. A fim de contribuir com a mudança do cenário descrito, políticas, programas e outras iniciativas estão emergindo em prol do incentivo e promoção da participação feminina nas áreas de Computação e tecnologias, no âmbito da educação e do mercado de trabalho. Um exemplo desse tipo de iniciativa ocorreu em 2015, com a presença de 193 líderes mundiais (incluindo representante do Brasil), que se comprometeram com 17 
metas globais para alcançar 03 objetivos nos próximos 15 anos: erradicar a pobreza extrema, combater a desigualdade e a injustiça, e conter as mudanças climáticas. Entre as 17 metas globais, está a meta 05 "Igualdade de Gênero: alcançar a igualdade de gênero por meio do fortalecimento das mulheres e meninas" [SDG 2015]. Neste contexto, o Programa Meninas Digitais [PMD 2019] foi institucionalizado pela Sociedade Brasileira de Computação (SBC) em 2015 com o objetivo de promover a equidade de gênero nas carreiras e cursos de Computação e tecnologias, buscando também motivar jovens de Ensino Médio a seguir carreira nessas áreas.

Para viabilização desta iniciativa em território nacional, o projeto conta com a colaboração de grupos multiplicadores desta proposta, que propõem projetos relacionados em suas instituições e estabelecem parcerias, de forma a disseminar esta ideia e executar ações. Nesse aspecto, a Universidade Federal de Mato Grosso (UFMT), Câmpus de Rondonópolis, em 2016, iniciou suas ações vinculadas ao programa nacional realizando um encontro do Projeto Meninas Digitais - Regional Mato Grosso como parte da programação de um evento de computação. Ainda, na referida instituição, em 2017, criou-se um grupo denominado Techno Girls, para representar a iniciativa local, criado e apresentado oficialmente durante um Fórum Meninas Digitais com abrangência regional.

Em 2018, uma ação desse grupo foi formalizada na forma de Programa de extensão universitária, o qual foi oficialmente proposto e executado pela primeira vez, com apoio do Programa de Bolsa de Extensão para Ações Afirmativas (PBEXT AF). Nessa direção, o presente Programa de extensão marca o início das atividades do grupo, voltadas às ações pela igualdade de gênero em tecnologia da informação, buscando priorizar indivíduos e populações em situação de vulnerabilidade social, em decorrência de sua condição de gênero e de pobreza. Além disso, a execução do Programa também contribui para a formação dos alunos e alunas participantes da equipe organizadora, uma vez que coloca em prática os conhecimentos adquiridos nas disciplinas de programação de computadores (Algoritmos I, Algoritmos II), Computadores e Sociedade, entre outras. O Programa aqui relatado desenvolveu ações na forma de oficinas diversas, abordando tecnologia e ensino de programação, apresentadas neste artigo.

As seções deste artigo estão organizadas da seguinte forma: na Seção 2, constam materiais e métodos; a Seção 3 traz breve fundamentação teórica sobre a Aprendizagem Dialógica; na Seção 4, são apresentados alguns trabalhos correlatos; a Seção 5 reporta os relatos de experiência; e, a Seção 6 discorre sobre as considerações finais.

\section{Materiais e métodos}

O Programa Techno Girls realizou suas atividades em 2018, no período de maio e dezembro. A equipe organizadora foi composta por 03 professores ( 01 coordenador e 02 colaboradores), 03 estudantes bolsistas de extensão, e 03 estudantes do grupo Programa de Educação Tutorial (PET), sendo todos vinculados a um curso de Sistemas de Informação da universidade proponente. No total de 09 membros da equipe, 05 eram homens e 04 mulheres.

O Programa foi estruturado em 8 encontros de 3 horas, duas vezes por semana. Dessa forma a participação nos 8 encontros gerou certificado de 24 horas. Os encontros 
foram estruturados da seguinte forma: $\left(1^{\circ}\right)$ Mulheres na computação; $\left(2^{\circ}\right)$ Noções fundamentais de Hardware; $\left(3^{\circ}\right)$ Noções fundamentais de Software; $\left(4^{\circ}\right.$, $5^{\circ}$, e $6^{\circ}$ ) Programação em Python; $\left(7^{\circ}\right)$ Perspectivas de mercado de trabalho em computação; e, $\left(8^{\circ}\right)$ Filme e debate sobre a participação de mulheres na área de exatas. Nas subseções a seguir constam descritos cada um desses conteúdos.

\section{Aprendizagem dialógica}

O grande diferencial das Oficinas foi a utilização da abordagem metodológica da mediação dos encontros com Aprendizagem Dialógica (Seção 3), trazido pelo professor coordenador do Programa, a partir de suas experiências com o projeto Comunidades de Aprendizagem [Mello, Braga, Gabassa 2012].

O conceito Aprendizagem Dialógica surgiu do resultado de muitos estudos e práticas investigativas no CREA (União Europeia) - Community of research on excelence for all,), da Universidade de Barcelona/Espanha [CREA 2019], na Universidade de Barcelona (Espanha). O enfoque do conceito tem a preocupação e o cuidado de desenvolver uma metodologia de ação participativa, na qual a manifestação que as pessoas têm em seus contextos da vida cotidiana seja igualmente valorizada no espaço escolar [Elboj et al. 2002]. O conceito de Aprendizagem Dialógica [Flecha 1997] se apresenta estruturado por sete princípios fundamentais, são eles: (1) Diálogo Igualitário; (2) Inteligência Cultural; (3) Transformação; (4) Dimensão Instrumental; (5) Criação de Sentido; (6) Solidariedade; e, (7) Igualdade de Diferenças.

O primeiro princípio, Diálogo Igualitário, é considerado um instrumento de aprendizagem amplamente reconhecido. Ele está em sintonia com a ação comunicativa, proposta por Habermas [1987]. Neste tipo de ação cada pessoa faz suas próprias contribuições ao diálogo. As falas não são classificadas como melhores ou piores, mas apreciadas como diferentes. Esse princípio confere à atividade educativa uma nova maneira de estabelecer-se: o que vale a partir deste modelo é a força que tem cada argumento e não o poder que ocupa a pessoa que o apresenta.

Com relação ao segundo princípio, Inteligência Cultural, Flecha [1997] destaca o fato de que todas as pessoas têm as mesmas capacidades para participar em um diálogo igualitário, mesmo que cada uma possa demonstrar essas capacidades em ambientes distintos. Isso significa que cada pessoa tem uma inteligência que é reportada ao contexto em que vive, e que se pode seguir aprendendo ao longo de toda a vida.

O terceiro princípio diz respeito à transformação da relação entre as pessoas e o seu entorno. A maneira de aprender gerada a partir do diálogo igualitário acaba por transformar as pessoas e o conceito que têm de si mesmas e das instituições em que vivem. A escola, nesta perspectiva, também passa a ser transformadora. Este conceito está presente na abordagem dialógica e diz respeito a uma forma de conceber a aprendizagem, que tem por objetivo estudar as transformações sociais e culturais e garantir uma educação de qualidade e igualitária para todas as pessoas frente aos desafios encontrados na sociedade atual.

O quarto princípio, Dimensão Instrumental, apresenta-se na aprendizagem, por meio do diálogo, de conhecimentos acadêmicos e instrumentais, pois a aprendizagem dialógica inclui todos os conhecimentos que são necessários para a sobrevivência na 
sociedade atual. A aprendizagem instrumental não se opõe ao diálogo. Ao contrário, ela se intensifica a partir da aprendizagem dialógica.

O quinto princípio, criação de sentido, insere-se no contexto da sociedade atual, que favorece e alimenta o individualismo e isso contribui para que muitas pessoas percam o sentido de suas vidas. A vivência a partir da Aprendizagem Dialógica possibilita reformular um novo sentido, não só individualmente, mas também do coletivo, como é o caso da escola. No que se refere ao sexto princípio, a Solidariedade, considera-se que precisa ser estimulada e construída. Assim como propicia ações mais individualistas frente a esse novo contexto, também se aprende a ser menos humanos e menos solidários, pois a sociedade "seleciona" os melhores e exclui o resto das pessoas. Por fim, o sétimo princípio concerne à Igualdade de Diferenças que indica que a verdadeira igualdade inclui o mesmo direito que cada pessoa tem de ser e viver de forma diferente. Por isso, todas as pessoas que participam do diálogo têm o igual direito de ser diferentes.

A concepção do processo de interações entre professores, bolsistas e voluntários, bem como dos estudantes participantes das oficinas foi pautada nos princípios da Aprendizagem Dialógica, sendo o princípio do Diálogo Igualitário o principal eixo condutor, uma vez que converge com as concepções de uma educação transformadora voltada para o atendimento de um público jovem contemporâneo, no qual a horizontalidade das relações se coloca em todos os espaços de interação de ensino e aprendizagem.

\section{Trabalhos correlatos}

Cesario et al. [2017] realizaram revisão sistemática na décima edição do Women in Information Technology (WIT), buscando conhecer quais estados brasileiros contavam com projetos relacionados ao tema, quais instituições estavam envolvidas e quais ações foram realizadas nesses projetos. Como resultado, os autores mostram que nem todos os estados apresentavam projetos, no entanto, todas as regiões brasileiras contavam com iniciativas dessa natureza. No total, 09 instituições (UCS, Unipampa, IFRS, UFSC, UFF, IFMT/UFMT, UnB, UFRN) eram proponentes de um projeto cada e outras 02 (UTFPR e UFAM) eram proponentes de dois projetos cada. Dentre essas instituições, quatro não eram relacionados ao Programa Meninas Digitais da SBC. No que se referem às ações realizadas, em maior número foram Oficinas, com 13 ocorrências, seguidas por palestras (06), workshops (02), fórum (01) e curso à distância (01). Os conteúdos abordados nas oficinas foram diversos, tais como, programação, raciocínio lógico, eletrônica, interação humano-computador, dentre outros.

Santos et al. [2017, p. 1253] mencionam que a intenção do Projeto Meninas Digitais da Bahia é a "popularização da Computação entre as mulheres, considerando também a participação dos homens, de modo a mostrar que a Computação deveria ser um espaço para todos, sem distinção de gênero, raça, etnia e sem limitações de disciplinas e/ou temas”. Dentre as ações realizadas, os autores citam: Mesa redonda "Meninas Digitais: para além dos estereótipos (de gênero, raciais e étnicos) nas práticas sociais e educacionais; Workshop do Dia do Estudante em uma escola estadual; Minicurso "Desenvolvendo Aplicativos para Android com App Inventor"; Mesa redonda "A participação feminina na tecnologia"; Lançamento da fanpage do projeto de 
extensão; e, Realização de cursos de iniciação à Programação de Computador (CIProg) com turmas exclusivas para mulheres. Para a realização das ações fizeram parte do planejamento: criação de identidade visual do projeto, divulgação, sistema de acompanhamento e avaliação, plano/roteiro para a realização das ações, desenvolvimento de materiais didáticos, e captação de recursos.

Ferreira et al. [2018] realizaram seu projeto em uma cidade do interior do Ceará, em uma zona periférica da cidade de Aracati, cujos moradores possuem, em sua maioria, baixa renda e não contam com ofertas de formação na área de Informática. $O$ projeto foi composto por 05 etapas, a saber: (1) Organização e montagem da infraestrutura de execução do projeto; (2) Delineamento do perfil da comunidade atendida; (3) Realização de curso na área de TIC; (4) Atividade com jogos de tabuleiro; e, (5) Encerramento do projeto. No total, 08 mulheres foram atendidas, sendo que estas consideraram a ação positiva, passando a utilizar o laboratório montado em outros horários, diferentes da realização do curso ofertado.

Silva e Silva [2018] relatam experiências ocorridas em três anos de realização de projeto. No primeiro ano, em 2015, o interesse foi de conhecer a realidade local com aplicação de questionário, criação de página no Facebook e participação das extensionistas na conferência Latinity (Latin American Women in Technology); no segundo ano (2016), a intenção foi de atrair meninas com duas ações: mesa redonda $H e$ For She, incluindo meninos nas discussões sobre o tema, e ensino lúdico de programa em blocos com o Google CWC (Coding With Chrome) em uma disciplina da matriz curricular de ensino médio técnico; e o terceiro ano (2017), o objetivo foi de inserir os participantes em competições, portanto, contemplou treinamentos semanais de estudantes de ambos os sexos, sendo que ao final houve participação na etapa nacional da Olimpíada Brasileira de Informática (OBI) e na Collegiate Cup Brazil.

Os trabalhos correlatos mencionados inspiram e trazem ideias para a realização das ações realizadas no presente Programa Meninas Digitais local, no sentido de conferir importância à divulgação das ações por meio de website próprio ou página em redes sociais, de ofertar oficinas, de também trazer os meninos para discussões e participação, de tentar minimizar questões associadas a outros tipos de discriminações, e de levantar metodologias de aplicação e outros tipos de ações que podem ser realizadas.

\section{Relato da experiência}

No total, as oficinas foram oferecidas em 03 turmas, com 08 encontros de 03 horas cada, no período da tarde, das 14 às 17 horas. Foram realizadas oficinas para turmas de estudantes de uma escola pública estadual que moram no entorno escolar e que é também o entorno da universidade e, portanto, o deslocamento dos alunos para o local das oficinas foi facilitado por estar próximo às suas casas. As inscrições foram feitas diretamente na escola. A estratégia para atingir o público feminino foi limitar $50 \%$ das vagas para os meninos em relação às meninas inscritas em cada turma, mesmo que houvessem mais meninos interessados. Todas as turmas oferecidas conseguiram atingir essa meta de $50 \%$ de inscrições de cada sexo.

No total, 91 (noventa e um) alunos se inscreveram nas oficinas, embora nem todos tenham participado de todos os encontros, considera-se que a ação foi efetiva no 
quesito formação para quem participou de qualquer encontro que seja. Permaneceram até o final 16 meninos e 14 meninas. Portanto, a taxa de formação final por gênero, num total de 30 participantes foi $53,33 \%$ para o gênero masculino e $46,66 \%$ para o gênero feminino.

\subsection{Primeiro encontro: Mulheres na Computação}

O objetivo de realizar as oficinas "Mulheres e computação - dos primórdios aos dias atuais" foi o de apresentar sobre a história da computação, na qual foram destacados os papéis femininos e sua importância para o desenvolvimento da área, cujo conteúdo foi preparado para ser apresentado em um encontro.

$\mathrm{O}$ encontro foi dividido em quatro partes. Inicialmente foi o momento de recepção, no qual foi feita a apresentação do grupo e do cronograma da oficina e, visando diferenciar o momento de uma aula tradicional e o diálogo igualitário - um dos princípio da aprendizagem dialógica -, os participantes foram organizados em um círculo. Para a integração da turma, foi realizada uma dinâmica chamada 'O quê você faria?' que acontece da seguinte maneira: cada participante (ministrantes e ouvintes) recebe um papel, no qual este deve escrever uma pergunta sobre o quê outra pessoa presente faria se estivesse em uma determinada situação; por exemplo, "o quê você faria se pudesse se teletransportar?". Após isso, todas as perguntas são colocadas em um recipiente e, por sorteio, distribuídas aos participantes. Sorteadas as perguntas, foi orientado aos participantes a responderem, no mesmo papel, a pergunta que receberam. Por último, cada participante deveria se apresentar, fazer a pergunta e solicitar que outra pessoa respondesse com a resposta que havia escrito para outra pergunta. A aleatoriedade de perguntas e respostas gerou momentos de descontração.

No segundo momento foi tratado da história da computação. Foram utilizados slides e cartões impressos com imagens e descrição de fatos ou de personagens da história da computação, por exemplo: o primeiro algoritmo criado, quem foi Ada Lovelace, etc. Os cartões foram distribuídos aos participantes que, de acordo com a ordem cronológica guiados pelos slides, deveriam ler ou explicar com sua interpretação o que ou quem era na descrição. Considerando o princípio de criação de sentido da Aprendizagem Dialógica, alguns fatos e/ou personagens foram selecionados considerando o contexto das tecnologias atuais, por exemplo, a invenção do smartphone e a origem das redes sociais. Ao final do momento, foi proposto aos participantes que reunissem os cartões e organizassem em ordem cronológica sem consultar as datas impressas no verso. O material utilizado foi adaptado do jogo Computasseia (2019).

No terceiro momento tratou-se sobre as percepções sobre o futuro da tecnologia. Esse momento contou com maior interação verbal dos aprendizes, pois ocorreu como uma roda de conversa, cujo tema gerador foram vídeos sobre tecnologias futuristas, tais como, robôs inteligentes e trem supersônico. Para mediar a roda de conversa foi utilizada a estratégia do Diálogo Igualitário, um dos princípios da Aprendizagem Dialógica. Essa estratégia estabelece o papel de um mediador para controlar inscrições e distribuir a oportunidade de fala buscando a igualdade de gênero, raça, etc., evitando também o protagonismo de pessoas que têm mais disposição para falar em público. Aos 
participantes foi indagado quais eram suas impressões sobre tecnologias tão inovadoras, alguns relataram sentimentos de expectativas e outros de apreensão.

No último momento foram apresentadas mulheres que se destacaram na tecnologia da informação. $\mathrm{Na} 1^{\mathrm{a}}$ oficina, foram apresentadas mais mulheres não brasileiras, a partir da $2^{\mathrm{a}}$ oficina, foram selecionadas apenas mulheres brasileiras, incluindo mulheres negras.

\subsection{Segundo encontro: Noções fundamentais de Hardware}

$\mathrm{Na}$ primeira parte da oficina foram apresentados conceitos acerca do hardware e o funcionamento dos componentes do computador, mostrando memórias, placas de vídeo, processadores, etc., a fim de fazê-los ter contato físico e visual peças reais, pois na maioria das vezes estão dentro de um gabinete e não podem ser manuseados facilmente. Logo após, foram apresentados vídeos mostrando a evolução dessas máquinas e apontando possíveis mudanças para o futuro.

Após isso, como parte do planejamento da oficina, foi realizada a primeira dinâmica. Primeiramente, as noções básicas teóricas sobre números binários foram apresentadas, visto que é a representação comunicativa entre máquinas. Em seguida, equipes foram formadas para realizar exercícios de conversão de números binários para decimais e decimais para binários, o que atendeu ao princípio da Dimensão Instrumental. Ainda com relação aos números binários, quebrando a ideia tradicional da oficina centrada no professor, uma segunda atividade foi proposta envolvendo todos da sala a irem até a frente com plaquinhas simbolizando os números e os bits, decimais e binários para uma demonstração mais dinâmica e ilustrativa. Essa dinâmica foi sugerida na obra Computação Desplugada [Unplugged, 2019].

$\mathrm{Na}$ sequência, iniciou-se o conteúdo de classificação dos computadores e de tecnologias de sistemas embarcados. Com esse conteúdo notou-se grande curiosidade por parte dos alunos nestas áreas, sendo o maior interesse em realidade virtual. Outro vídeo sobre tecnologias do futuro foi disponibilizado, seguido pela aplicação de um quiz, em que as equipes responderam perguntas visualizadas em projeção em tempo real e um ranking era atualizado a cada pergunta. $\mathrm{O}$ mais interessante foi ver que os alunos já interagiam entre si, mesmo não estando no mesmo grupo da atividade, sempre respeitando a igualdade de diferenças, numa relação sadia e de transformação. $O$ software utilizado para o quiz foi o Kahoot [2019].

\subsection{Terceiro encontro: Noções fundamentais de Software}

Neste encontro, foram utilizados os mesmos métodos e cronograma apresentados na oficina de hardware, a diferença foi no conteúdo, sendo a primeira parte abordando sobre o início da computação, as primeiras linhas de código, dentre elas, a importância da contribuição da Pesquisadora Ada Lovelace. Foi abordado sobre os Sistemas Operacionais, seus conceitos, recursos, importância e exemplos didáticos.

Em seguida, uma dinâmica foi realizada para demonstrar a comunicação entre programas. Para isso, grupos foram formados, definindo um programa ou hardware para cada pessoa, ou seja, a pessoa fazia o papel de tal função. O objetivo era realizar 
operações matemáticas seguindo os números que chegavam na ordem correta para o aluno que fazia o papel de SO para ele solucionar, o que exigia rapidez por parte dos grupos para completar tal missão.

$\mathrm{Na}$ segunda parte foram abordados os conceitos de software aplicativo, realizando uma roda de conversa sobre os aplicativos mais usados, na qual os estudantes disseram o que gostavam ou não gostavam em cada um, sugestões para melhorias, dentre outras. Após isso, vários softwares existentes em diversas áreas profissionais foram apresentados, mostrando que a tecnologia está presente em diversos segmentos sociais, tais como as áreas jurídica, administrativa, comercial, agrícola e educacional, entre outras.

Finalmente, conceitos e conhecimentos básicos sobre a internet foram discutidos e um vídeo de curta metragem sobre sua história foi veiculado. O encerramento da oficina sobre software foi efetuado com a proposta de desenho, em uma folha A4, de uma ideia sobre algum software, deixando por conta da imaginação, poderia ser uma tela de um aplicativo, um personagem em um game, ou outro.

\subsection{Quarto ao oitavo encontro: Programação em Python}

No quarto encontro foi apresentada uma breve explicação sobre os comandos básicos de programação em Python, com o intuito de familiarizar os participantes com os recursos da linguagem, pois seriam essenciais para as próximas oficinas de jogos. $\mathrm{O}$ jogo CodCOMBAT [2019] foi utilizado para introduzir noções de lógica e de programação. Com esse jogo os alunos tiveram a oportunidade de completar diversos códigos para passar por fases e assim trabalhar o raciocínio lógico

No quinto encontro foi o momento em que os participantes tiveram contato com os jogos em Python e a biblioteca gráfica PyGame [2019]. Eles receberam mais algumas orientações sobre a linguagem que estava sendo utilizada e sobre o funcionamento da biblioteca, assim como a relação entre eles. Esta etapa permitiu que os participantes pudessem ter acesso ao jogo Snake, que tem como objetivo fazer uma cobrinha comer quantas maçãs conseguir sem que se chocar com a parede, e o Jogo da Velha, o tradicional jogo de tentar marcar sequências distintas de 3 caracteres $\mathrm{X}$ ou $\mathrm{O}$ para vencer o jogo.

No sexto encontro foi dada continuidade à ideia da atividade do encontro anterior, no qual foram relembrados os conhecimentos da linguagem Python e apresentada uma nova biblioteca gráfica chamada Tkinter, que acompanha a distribuição oficial do interpretador Python. Os participantes puderam entender os algoritmos de funcionamento dos jogos Pong - em que se tem uma haste que toca a bola para a parte de cima da tela, evitando que a bola caia e o jogo acabe, e também os algoritmos de funcionamento do jogo da Forca;

No sétimo encontro foram apresentadas algumas áreas em que os alunos do projeto podem atuar na tecnologia, informações de faixa salarial aproximadamente e as instituições educacionais que oferecem cursos da área em questão desde o básico a uma graduação aqui em nossa cidade, também foram utilizados vídeos sobre profissões no ramo da tecnologia e, para finalizar, os participantes responderam a um quiz no Kahoot, 
com perguntas sobre todo conteúdo apresentado desde o início das oficinas como forma de avaliação.

No último encontro o filme "Estrelas Além do Tempo" foi escolhido e veiculado por se encaixar no tema do projeto sobre a presença das mulheres em área de exatas, tais como: matemática, computação e engenharia.

\section{Considerações finais}

Destaca-se a importância de trazer temas e discussões que apresentaram o papel das mulheres na Computação para os estudantes do sexo masculino, uma vez que as reflexões surgidas puderam contribuir para que possam aprendem a valorizar o papel feminino nas ciências e assim refletirem também sobre a quebra do paradigma de que as mulheres são menos capazes que os homens das áreas de exatas. Tais discussões também foram importantes para estimular estudantes do sexo feminino nas diversas áreas que a tecnologia da informação atua, com destaque para a área de desenvolvimento de jogos, que é uma área atrativa para o público alvo do programa. Os alunos puderam compreender o funcionamento do ambiente de desenvolvimento dos jogos e o trabalho dos desenvolvedores de jogos e tiveram a oportunidade de realizar diversos tipos de testes, modificando parâmetros nos códigos dos jogos, tais como: alterações de cor, velocidade, movimento, objetos, dentre outros parâmetros.

A mediação das interações de aprendizagem com os princípios da Aprendizagem Dialógica contribuiu significativamente para que desenvolvimento das atividades pudessem também garantir espaço de fala de forma igualitária, especialmente levando-se em conta que no contexto atual a fala das mulheres é facilmente suprida pela fala dos homens. A atividades de preparação de material e execução dos encontros na forma de oficinas dialógicas constituíram também importante oportunidade de experiências de iniciação à docência dos alunos do curso de Sistemas de Informação, tendo em vista que muitas atividades realizadas profissionalmente demandam tais habilidades porém, por ser um curso de bacharelado, dificilmente os alunos podem experimentar tais oportunidades de docência, visto que a formação não é direcionada para essa finalidade.

Como produtos gerados a partir da execução do Programa no ano de 2018, têm-se os seguintes: website (https://technogirlsufmt.wixsite.com/technogirls), material de divulgação, página em rede social, materiais didáticos e resumos publicados e apresentados em eventos locais.

\section{Referências}

Cesario, Gisela; et al. 2017. Por Mais Mulheres na Computação: análise dos trabalhos publicados no $\mathrm{X}$ Women in Information Technology. Anais do $11^{\circ}$ Women in Information Technology (WIT), XXXVII Congresso da SBC, Porto Alegre: SBC.

CodeCombat. Disponível em: https://codecombat.com/, acesso dia 14/03/2019.

Computasseia. Disponível

em: http://gameinclass.ic.ufmt.br/computassy/content/files/cartas-A3.pdf

CREA. 2019 Centro Especial en Teorías y Prácticas Superadoras de Desig 
CSUnplugged. (2019). “Computer Science Unplugged”. Disponível em: https://csunplugged.org/en/ Acesso em 15/03/2019.ualdade. Disponível em: https://crea.ub.edu/index/?lang=es, acesso dia 14/03/2019.

Elboj, C., et al. 2002. Comunidades de aprendizaje. Transformar la educacióm. Bacelona: Graó.

Ferreira, Helen Abdala R.; et al. 2018. Metodologia de um Projeto de Extensão para Inclusão, Desmistificação e Empoderamento de Jovens Mulheres em Tecnologias da Informação e Comunicação. Anais do $12^{\circ}$ Women in Information Technology (WIT 2018), XXXVIII Congresso da SBC, Porto Alegre: SBC.

Flecha, R. 1997. Compartiendo Palabras: el aprendizaje de las personas adultas através del diálogo. Barcelona: Paidós.

Grossi, Márcia G. R.; Borja, Shirley D. B.; Lopes, Aline M.; Andalécio, Aleixina Maria L. 2016. "As mulheres praticando ciência no Brasil". Rev. Estud. Fem. vol.24 no.1 Jan./Apr.. Disponível em: https://goo.gl/fe956c, acesso dia 14/03/2019.

Habermas, J. 1987. Teoría de la Acción Comunicativa. Vol. I: Racionalidade de la acción y racionalización social. Madrid, Taurus.

Kahoot. Disponível em: https://kahoot.com/, acesso dia 15/03/2019.

Mello, R.R.; Braga, F.M.; Gabassa, V. (2012) Comunidades de Aprendizagem: outra escola é possível. São Carlos, EdUFSCar.

PMD. 2019. Programa Meninas Digitais. Sociedade Brasileira de Computação (SBC). Disponível em: http://meninas.sbc.org.br/, acesso dia 06/03/2019.

Posser, Camila V.; Teixeira, Adriano C. 2016. Mulheres que aprendem informática: Um estudo de gênero na área de TI. Anais do XXII Workshop de Informática na Escola (WIE), V CBIE. Disponível em: https://goo.gl/VXamoE, acesso dia 14/03/2019.

PyGame. Disponível em: https://www.pygame.org/, acesso dia 14/03/2019.

Santos, Juliana Maria O. dos; et al. 2017. Meninas Digitais - Regional Bahia: os primeiros bits. Anais do $11^{\circ}$ WIT - Women in Information Technology, XXXVII Congresso da SBC, Porto Alegre: SBC.

SDG. 2015. About the Sustainable Development Goals. United Nations. Disponível em: https://goo.gl/gTmMxC, acesso dia 14/03/2019.

Silva, Thais Regina de M. B.; Silva, Gláucia Braga e. 2018. Programando para inclusão - experiências e lições aprendidas. Anais do $12^{\circ}$ Women in Information Technology (WIT 2018), XXXVIII Congresso da SB, Porto Alegre: SBC. 